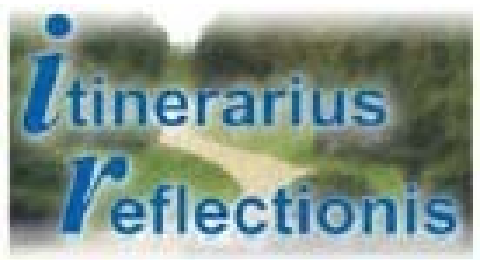

Revista Eletrônica de Educação do Curso de Pedagogia do Campus Jataí da Universidade Federal de Goiás

[Vol I - n.4 ] [jan/jul] [ 2008]

\title{
O ESTÁGIO SUPERVISIONADO NA EDUCAÇÃO INFANTIL: DESAFIOS E PERSPECTIVAS.
}

\author{
RAIMANN, Elizabeth Gottschalg. Mestre em Educação Brasileira, professora do Curso de \\ Pedagogia - Campus Jataí/UFG.
}

\section{RESUMO:}

A concepção de estágio supervisionado foi se transformando na medida em que se problematizava o papel da didática e da prática de ensino nos cursos de licenciatura. O estágio supervisionado passou por diferentes concepções as quais ainda estão presentes, de certa forma, hoje nos cursos de Pedagogia levando muitas vezes o estágio, erroneamente, a ser considerado como algo desnecessário ou sem grande importância. Atualmente, com a aprovação das Diretrizes Curriculares Nacionais para a Pedagogia - CNE/CP nº5/2005 de 20/12/2005 -, abrem-se perspectivas e possibilidades para o estágio ter seu papel de importância na formação do professor de Educação Infantil e nos anos iniciais do Ensino Fundamental. O presente trabalho objetiva discutir o valor do estágio supervisionado no curso de Pedagogia considerando o seu contexto histórico, a sua importância na profissionalização do docente e a sua organização didática pedagógica. Por meio da pesquisa bibliográfica pautada em Piconez (1991), Freitas (1996) e Ostetto (2000) buscou-se problematizar as práticas presentes nas propostas do estágio supervisionado ao longo de sua existência nos cursos de pedagogia e, ao mesmo tempo, apontar para o estágio enquanto um espaço da Práxis. Desta forma, o estágio não deveria ser visto como aprendizado, mas, mais do que isso, como trabalho. Assim, o trabalho concebido enquanto Práxis seria o eixo articulador entre a prática de ensino e o estágio supervisionado. Quanto às etapas do estágio, desde o projeto de trabalho até a sua efetivação, estas deveriam ser elaboradas no coletivo, de forma participativa, a partir da realidade da instituição infantil e considerando o corpo docente, administrativo, técnico auxiliar, alunos estagiários e professor orientador. Essa proposta leva a leitura das práticas e da vida, envolvendo o ouvir e o sentir as crianças e os profissionais envolvidos numa relação dialógica e humana. Portanto, estágio, se entendido como Práxis, deveria possibilitar um espaço para debates, reflexões e aprendizados tanto para os alunos estagiários quanto para os demais envolvidos sejam eles a comunidade escolar seja o professor orientador de estágio.

Palavras-chave: prática de ensino, estágio supervisionado, formação docente.

\section{ABSTRACT:}


The notion of supervised internship was changing while the role of didactics and teacher training was problematized in the teaching degree courses. The supervised internship underwent different notions which are still present, somehow, in the Pedagogy courses, often leading the internship, wrongly, to be considered something unnecessary or skin-deep. Currently, with the passing of the National Curricular Lines of Direction for Pedagogy - CNE/CP $n^{\circ}$ 05/2005 de 20/12/2005 -, perspectives and possibilities are open for the internship to have its role in the training of Basic Education teachers. This paper aims to discuss the value of the internship in the Pedagogy course taking into account its historical context, its importance in the teachers' professionalization and its pedagogical didactical organization. Based on the bibliographical research methodized by Piconez (1991), Freitas (1996) and Ostetto (2000), the present practices in the proposals of the supervised internship through their existence in the Pedagogy courses were problematized. Also, the internship as a space of praxis was highlighted. In this manner, the internship should not be seen as learning, but, much more, as a paper project. Thus, this paper taken as praxis would be the main point between the teaching practice and the supervised internship. When it comes to the internship stages, from the paper project to its execution, they should be elaborated collectively, in a participating way, based on the reality of the children institution and considering the teaching and the registrar's staff, and the internship students and their tutor. This approach leads to the reading of practices and life itself, engaging the hearing and sensing the children and professionals involved in a dialogical and human relation. Therefore, internship, if understood as praxis, should offer a space for debates, reflections and learning both for internship students and others involved such as the school community or the internship tutor.

\section{Key-words: teaching practice, supervised internship, teacher training}

\section{Introdução}

Ao tratar do estágio supervisionado presente no Curso de Pedagogia faz-se necessário, em primeiro momento, situá-lo num contexto histórico e educacional, na própria licenciatura entendendo que a Pedagogia não escapa das influências sociais, econômicas e políticas ao longo de sua existência. Em seguida, num segundo momento, trataremos do estágio enquanto instrumento fundamental na formação e profissionalização do professor, e, por último, o estágio supervisionado na Educação Infantil enquanto elaboração, desenvolvimento, avaliação e relatório final de projeto de trabalho.

O estágio supervisionado passou por diferentes concepções as quais ainda estão presentes, de certa forma, hoje nos cursos de Pedagogia. Atualmente, com a aprovação das Diretrizes Curriculares Nacionais para a Pedagogia - CNE/CP nº5/2005 de 20/12/2005 -, abrem-se 


\section{tinerarius}

Revista Eletrônica de Educação do Curso de Pedagogia

do Campus Jataí da Universidade Federal de Goiás

[Vol I - n.4 ] [jan/jul] [ 2008]

\section{T}

ISSN: 1807-9342

perspectivas e possibilidades para o estágio ter seu papel de importância na formação do professor de Educação Infantil e nos anos iniciais do Ensino Fundamental.

\section{O estágio supervisionado e suas concepções}

A concepção de estágio supervisionado foi se transformando na medida em que se problematizava o papel da didática e da prática de ensino nos cursos de licenciatura. Dentre as concepções, destacamos aquelas apresentadas por Piconez (1991) e Freitas (1996), ao tratarem do papel do estágio supervisionado no curso de Pedagogia.

Segundo Piconez (1991), pouco ou nada o estágio contribuiu para a formação do professor, considerando que houve uma separação entre a teoria e a prática na organização das disciplinas na matriz curricular dos cursos de Pedagogia. Ou seja, primeiro se apresentavam as disciplinas teóricas e, posteriormente, as práticas, ao final do curso, cabendo à didática ou à prática de ensino a responsabilidade pelo estágio.

Além do mais, as orientações por parte dos professores, no estágio, partia de uma agenda pré-estabelecida por eles sem a discussão prévia das partes envolvidas. Esse distanciamento entre teoria e prática e o lugar que coube ao estágio fizeram com que este fosse considerado ou uma atividade menor ou uma tábua de salvação dos futuros professores ou, ainda, uma panacéia para todos os problemas que o curso não soube resolver. Segundo o levantamento realizado por Freitas (1996), cabia ora à didática ora à prática de ensino responsabilizar-se pelo estágio e, como não poderia deixar de ser, recebia as influências da própria concepção dessas disciplinas.

Inicialmente, a visão da didática era técnico-instrumental, bem própria da concepção antes da década de 1980. Nesse caso, cabia ao estagiário aplicar na prática o que perdeu na teoria, como se fosse algo natural. Além do que a visão tecnicista não contextualizava os conteúdos; não havia uma visão crítica do próprio fazer e pensar.

Ainda conforme Freitas (1996), a didática foi colocada em questão no momento político educacional em que, com a abertura e a democratização, buscou-se rever a própria didática numa 


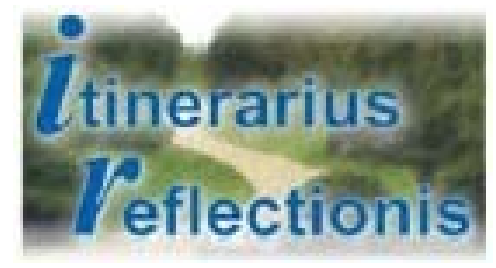

\section{Revista Eletrônica de Educação do Curso de Pedagogia do Campus Jataí da Universidade Federal de Goiás \\ [Vol I - n.4 ] [jan/jul] [ 2008] \\ ISSN: 1807-9342}

visão crítica/transformadora, sendo a didática, então, considerada não mais neutra, porém com intencionalidade.

Buscou-se, conforme contribuição de Vera Maria Candau (2000), a didática fundamental em detrimento da instrumental. Essa mudança, de certa forma, não alterou muito o próprio estágio, pois ainda se percebia esse como momento de se aplicar o que se aprendia na universidade, ou seja, levavam-se às escolas públicas as inovações metodológicas como forma de demonstrar a dimensão prática das teorias novas propostas pela comunidade acadêmica.

O estágio, segundo Piconez (1991), ainda não tinha encontrado seu lugar de importância, visto que as diferentes concepções não indicavam como articular teoria e prática. As práticas da realidade educacional não ajudavam os alunos a encontrar as explicações devidas, faltando-lhes fundamentos teóricos necessários para isso, ou então, apenas ratificavam o que já se sabia sobre a má formação dos professores em seus relatórios. Faltavam maiores argumentações. Diante disso, fica a questão imposta pelas autoras, Piconez e Freitas: como articular teoria e prática? Qual seria o eixo norteador para o estágio supervisionado?

Freitas (1996), em sua pesquisa referente ao estágio supervisionado, traz reflexões importantes para essa questão e considera que o estágio não deve ser visto como aprendizado, mas, mais do que isso, como trabalho. E afirma que o eixo articulador entre a prática de ensino e o estagio é o trabalho.

Nesse sentido, se faz necessário esclarecer de que lugar teórico a autora se posiciona para sua argumentação quanto ao trabalho. Freitas (1996) parte da concepção materialista-histórica, pautando-se em Marx. E assim afirma:

Compartilhamos da formulação de Marx (1975), que concebe o trabalho como todas as formas de atividade humana pelas quis o homem se relaciona com a natureza com o objetivo de transformá-la, apreendendo, compreendendo e transformando a realidade que o cerca sendo, neste processo, transformado por ela. O trabalho é um ato exclusivamente humano e, por ele o homem se diferencia e se distingue dos animais (FREITAS, 1996, p.37). 


\section{tinerarius}

\section{The}

ISSN: 1807-9342

Assim, a docência é trabalho que, como trabalho, transforma a natureza e as condições sociais que envolvem a sua existência. Pois o trabalho "apresenta-se como possibilidade concreta de articulação entre objetivação e apropriação. Os homens, ao se apropriarem da natureza, transformando-a [...], produzem seus meios de existência, objetivando-se no trabalho" (FREITAS, 1996, p.44).

No enfrentamento da dicotomia teoria-prática, a autora defende a práxis, ou seja, a atividade teórica-prática que se apresenta num constante processo de ação-reflexão levando a uma ação transformadora. Nessa perspectiva, o estágio deixa se ser treinamento ou aplicação de teoria para ser trabalho. E como trabalho é a possibilidade criativa e transformadora em que teoria e prática estão juntas a partir da realidade concreta dos envolvidos. É a possibilidade da vivência e do trabalho pedagógico que ocorrem de forma criativa e produtiva. Desta forma, o estágio é de fundamental importância na formação e profissionalização do professor.

Considerando as novas diretrizes curriculares para o curso de Pedagogia, o estágio supervisionado é aquele componente curricular a ser efetivado ao longo do curso de forma interdisciplinar, propiciando a pesquisa, ampliando os conhecimentos e habilidades além de atitudes éticas.

Embasada no princípio de que o trabalho é o articulador entre a teoria e a prática, passaremos a pensar no estágio, na educação infantil, pautada nas contribuições de Luciana Ostetto (2000), que parte da premissa de que a proposta de trabalho do estágio deve ser da forma de projeto de trabalho a ser construído no coletivo, ou seja, por todos os envolvidos na educação infantil. Nesse caso, os professores, a coordenação pedagógica, os auxiliares, os alunos estagiários, o professor orientador de estágio, a partir do contexto da instituição, numa perspectiva de troca e interlocução, como se verá mais à frente.

\section{O estágio supervisionado e a política educacional}

O estagio na educação infantil, hoje, envolvendo crianças de 0 a 6 anos, é algo recente. Passou a ter sua importância a partir da LDB 9394/96, ao ampliar o conceito de Educação Básica, 
incorporando a educação infantil no atendimento de crianças de 0 a 6 anos. O MEC elaborou documentos para o atendimento a essa faixa etária e, em 1998, editou o Referencial Curricular para a Educação Infantil, dando parâmetros de ação educativa a instituições e professores no seu trabalho. Procurou-se sair da visão assistencialista, até então muito presente na sociedade, para uma visão também educativa, considerando a criança tanto no cuidado quanto na educação visando sua totalidade física, emocional, intelectual e cultural.

Apesar da ampliação da Educação Básica na inclusão da educação infantil, conforme proposto pela LDB, é preciso salientar o impacto do FUNDEF - Fundo de Manutenção e Desenvolvimento do Ensino Fundamental e de Valorização do Magistério - nesse processo de política educacional. Seguindo a lógica da focalização do Estado para o ensino fundamental, a Emenda Constitucional $n^{\circ} 14 / 96$ cria o FUNDEF e os seus recursos são direcionados apenas para o ensino fundamental. Conforme se lê:

Art.60, parágrafo $1^{\mathrm{o}}$ : A distribuição de responsabilidades e recursos entre os Estados e seus municípios a ser concretizada com parte dos recursos definidos neste artigo, [...] e assegurada mediante criação [...] de um Fundo de Manutenção e Desenvolvimento do Ensino Fundamental e de Valorização do Magistério [...], parágrafo 2[...] e será distribuído entre cada Estado e seus Municípios, proporcionalmente ao número de alunos nas respectivas redes de ensino fundamental (CARNEIRO, 2001, p.205).

Segundo a LDB 9394/96, artigo 11, inciso 5, “Os municípios incumbir-se-ão de: [...] oferecer a educação infantil em creches e pré-escolas [...]" como se vê os municípios responsáveis, a princípio, pela educação infantil pouco ou não tiveram verbas para consolidar ou ampliar o atendimento às crianças de 0 a 6 anos.

Mesmo com as dificuldades apresentadas, o curso de Pedagogia buscou qualificar-se para o atendimento a esse nível de ensino, conforme preconizava a LDB em artigo referente à formação profissional e, no seu estágio, buscava aproximar estagiários da instituição de Educação Infantil e dos anos iniciais do Ensino Fundamental:

Art 62: A formação de docentes para atuar na educação básica far-se-á em nível superior, em curso de licenciatura, de graduação plena, em universidades e 


\section{tinerarius}

institutos superiores de educação, admitida, como formação mínima para o exercício do magistério na educação infantil e nas primeiras séries do ensino fundamental, a oferecida em nível médio, na modalidade Normal (CARNEIRO, 2001, p.149).

Atualmente é preciso considerar algumas mudanças: ampliação do ensino fundamental, abarcando crianças de seis anos; passagem do ensino fundamental para nove anos, conforme decreto presidencial Lei $\mathrm{n}^{\mathrm{o}} 11.274$ de 06/02/2006 ${ }^{1}$. Nesse contexto, será necessário rever e aprofundar as concepções de criança, as concepções de ensino-aprendizagem, dentre outros, conforme documento do MEC, intitulado Ensino Fundamental de nove anos: Orientações Gerais (SEB/MEC, 2004).

\section{O estágio supervisionado e suas etapas}

Considerando o estágio e sua constituição, em específico, estaremos, a seguir, pautadas no trabalho de Ostetto (2000), desenvolvido junto com suas alunas em escolas e instituições públicas, analisando cada parte que o constitui. Segundo Ostetto (2000), a elaboração do projeto de trabalho de estágio deve ser gestado no coletivo, de forma participativa, a partir da realidade da instituição infantil e considerando o corpo docente, administrativo, técnico auxiliar, alunos estagiários e professor orientador.

Anterior ao projeto, são necessárias outras etapas não menos importantes e que serão explicitadas a seguir. A primeira seria a aproximação da IES com a instituição infantil para firmarem parcerias de trabalho. A segunda é quando alunos estagiários vão à instituição infantil no intuito de conhecer, vivenciar e observar o cotidiano com mais profundidade. Nesse caso, a observação sai da mera constatação da realidade para ser uma observação investigativa, problematizadora da realidade, que faz a leitura das práticas e da vida e, assim, passa a ser participativa do cotidiano, envolvendo o ouvir e o sentir as crianças e os profissionais envolvidos numa relação dialógica e humana. Nessa etapa, é preciso que tanto orientador de estágio quanto

${ }^{1}$ Lei que altera a redação dos arts. 29, 30,32 e 87 da LDB 9394/96, dispondo sobre a duração de 9 (nove) anos para o ensino fundamental, com matrícula obrigatória a partir dos 6 (seis) anos de idade. 


\section{tinerarius}

estagiários discutam as diferentes concepções de estágio, do trabalho coletivo e da visão interdisciplinar considerando que isso é construído ao longo do trabalho.

A terceira etapa, então, seria a elaboração do projeto de trabalho do estágio, que é submetido à instituição e aos que nela trabalham. Assim, conforme Ostetto (2000), há contribuições, opiniões, sugestões, dificuldades apresentadas e alternativas oferecidas. Nesse diálogo defendido pela autora, permite-se que ambos os lados ganhem levando comprometimento, engajamento e trocas frutíferas, pois se irá pensar sobre, fazer melhor e decidir o como. Desse movimento, o projeto de trabalho do estágio vem, então, atender as crianças no cuidar e no educar, na formação em serviço e na formação de futuros professores.

Outra etapa, a seguir, seria o desenvolvimento do trabalho. Durante o desenvolvimento do projeto é preciso considerar que nada está cristalizado. O projeto precisa passar por constantes avaliações e redimensionamentos e propor alternativas, visto que a reflexão na prática leva a isso. Outra questão é o próprio registro de tudo desenvolvido, considerando as ações efetivas e concretas e as percepções, dúvidas e anseios. Esses registros, como num diário de bordo, permitem ao final a elaboração do relatório do projeto de trabalho e possíveis pesquisas a se desdobrar desse trabalho.

A avaliação, na seqüência da quinta etapa, não é pontual, porém ela ocorre ao longo do estágio visto como processo que engloba todos os participantes. Nesse sentido, permite-se uma visão mais ampla do trabalho, possibilitando um reencaminhamento, abrindo espaço para considerações para as partes envolvidas. Enquanto avaliação cabe a auto avaliação de todos os envolvidos no processo.

E, por fim, o relatório final, é última etapa do estágio. Esse documento é de fundamental importância e deve ser disponibilizado para a instituição parceira. Nesse relatório final, o estagiário apresenta sua análise, seu encaminhamento, seu relato de experiência. A socialização dos relatórios finais dos estagiários, em forma de seminário, permite o debate e a participação de outras pessoas interessadas procurando, assim, melhorar a qualidade do ensino e a qualificação profissional. 


\section{tinerarius}

Revista Eletrônica de Educação do Curso de Pedagogia

do Campus Jataí da Universidade Federal de Goiás

[Vol I - n.4 ] [jan/jul] [ 2008]

\section{0}

ISSN: 1807-9342

Cada etapa do estágio tem sua função e importância e deve ser levada com responsabilidade por todos. O estágio tem seus desafios e perspectivas. Enquanto perspectivas, no contexto em que foi discutido acima, permite um trabalho amplo e bem estruturado, pautado na pesquisa, contribuindo para a formação dos alunos, futuros professores, bem como com a instituição parceira como um todo.

Os desafios provêm das próprias relações que envolvem o estágio: há as dificuldades dos alunos estagiários em se envolver, pois muitos já são professores atuantes; a instituição parceira vê com desconfiança a presença dos alunos estagiários; o tempo nem sempre é tão disponível para um envolvimento de todos; e, por fim, há falta de compromisso com uma educação de qualidade e democrática da própria educação infantil.

\section{Considerações finais}

Apesar das dificuldades que envolvem a realização do estágio supervisionado, tanto sua elaboração quanto sua efetivação, é parte importantíssima na formação do futuro docente e mesmo daqueles que já exercem a docência.

O estágio, se entendido como Práxis, deveria possibilitar um espaço para debates, reflexões e aprendizados tanto para os alunos estagiários quanto para os demais envolvidos sejam eles a comunidade escolar seja o professor orientador de estágio.

Nessa perspectiva, o tempo reservado ao estágio supervisionado deveria ser caro a todos e melhor empregado, valorizando, assim, a docência e o próprio curso de Pedagogia.

\section{Bibliografia}

BRASIL. Conselho Nacional de Educação n5/2005 trata das Diretrizes Curriculares Nacionais para o Curso de Pedagogia.

BRASIL. Presidência da Republica - subchefia para Assuntos Jurídicos - Lei $\mathrm{n}^{\circ} 11.274$ de 6/02/2006 altera a redação dos arts.29,30,32 e 87 da lei nº394/96, dispondo sobre a duração de nove anos par o ensino fundamental com matricula obrigatória a partir dos seis anos de idade.

CANDAU, Vera Maria (org.). A didática em questão. 18 ed. Petrópolis: Vozes, 2000. 
Revista Eletrônica de Educação do Curso de Pedagogia do Campus Jataí da Universidade Federal de Goiás

[Vol I - n.4 ] [jan/jul] [ 2008]

ISSN: 1807-9342

CARNEIRO, Moaci Alves. LDB fácil de entender. 6.ed.Petrópolis:Vozes, 2001.

FREITAS, Helena Costa Lopes de. $\mathrm{O}$ estágio supervisionado como princípio articulador na prática de ensino e nos estágios. Campinas: Papirus, 1996.

OSTETTO, Luciana. Encontros e encantamentos na educação infantil. Campinas: Papirus, 2000.

PICONEZ, Stela Betholodo. A prática de ensino e o estágio supervisionado. Campinas: Papirus, 1991.

SECRETARIA DE EDUCAÇÃO BÁSICA/MEC. Ensino Fundamental de nove anos: Orientações Gerais. Julho de 2004. 27p. 